\title{
ANALISIS KEMAMPUAN PEMAHAMAN KOSEP MATEMATIS MELALUI MODEL PEMBELAJARAN MANDIRI PADA MATA KULIAH ANALISIS KOMPLEKS
}

\author{
Sudiyah Anawati \\ Pendidikan Matematika,Universitas Indraprasta PGRI Jakarta \\ diyahanna@gmail.com
}

\begin{abstract}
Abstrak
Penelitian ini dilatar belakangi oleh kesulitan mahasiswa dalam menerapkan konsep turunan fungsi komples dan khawatiran dosen terhadap kemampuan pemahaman konsep pada mata kuliah analisis kompleks selama pembelajaran jarak jauh (PJJ), sehingga peneliti mengunakan model pembelajran mandiri. Tujuan dari penelitian ini adalah untuk mendeskripsikan dan mengetahui kategori kemampuan pemahaman konsep matematis melalui metode pembelajaran mandiri. Penelitian menggunakan model penelitian deskripsi kualitatif. Subjek penelitian ini adalah mahasiswa kelas $7 \mathrm{C}$ program studi Pendidikan Matematika Universitas Indraprasta PGRI Jakarta. Teknik pengumpulan data dalam penelitian ini adalah tes pemahaman konsep matematika dan observasi menggunkan teknik analisis data kualitatif. Dari hasil tes yang diperoleh menunjukkan bahwa kemampuan pemahaman konsep matematis dalam kategori rendah 13,89\% (5 orang), kategori sedang 77,78\% (28 orang) dan kategori tinggi 8,33\% (3) orang. Sedangkan untuk rata-rata nilai kemampuan pemahaman konsep matematis mahasiswa adalah 44,14 termasuk dalam kategori sedang. Pengunaan model pembelajaran mandiri pada mata kuliah analisis kompleks menujukkan kemampuan pemahaman konsep dalam kategori sedang.
\end{abstract}

Kata Kunci : Metode pembelajaran mandiri, Kemampuan pemahaman konsep matematis.

\begin{abstract}
This research is motivated by the difficulty of students in applying the concept of complex function derivatives and lecturers' concerns on the ability to understand concepts in complex analysis courses during distance learning (PJJ), so that researchers use the independent learning model. The purpose of this study was to describe and determine the category of the ability to understand mathematical concepts through independent learning methods. The study used a qualitative descriptive research model. The subjects of this study were $7 C$ grade students of the Mathematics Education study program, Indraprasta University, PGRI Jakarta. Data collection techniques in this study were tests of understanding mathematical concepts and observations using qualitative data analysis techniques. From the test results obtained, it shows that the ability to understand mathematical concepts is in the low category 13.89\% (5 people), the moderate category is $77.78 \%$ (28 people) and the high category is $8.33 \%$ (3) people. Meanwhile, the average value of students' mathematical concept understanding ability is 44.14, including in the medium category. The use of independent learning models in complex analysis courses shows the ability to understand concepts in the medium category.
\end{abstract}

Keywords: Independent learning method, Ability to understand mathematical concepts.

\section{PENDAHULUAN}

Wabah Covid-19 berdampak pada metode pembelajaran saat ini. Sementara itu, pembelajaran secara asinkron dilakukan menggunakan applikasi seperti Google Classroom, Edmodo, WhatsApp, Email, zoom meeting, google meet, dll. Dosen mengunggah konten pembelajaran seperti bahan bacaan, video pembelajaran, ataupun tautan materi yang tersedia di web ke applikasi pembelajaran yang digunakan. Mahasiswa dapat memberikan tanggapan atau pertanyaan melalui fitur chat yang disediakan ataupun menggunakan WhatsApp (Firman, 2020). Pembelajaran jarak jauh (PJJ) yang tidak biasa dilakukan oleh mahasiswa dikhawatirkan dosen akan mempengaruhi tingkat kemampuan 
pemahaman konsep-konsep pada mata kuliah analisis kompleks.

Kemampuan pemahaman konsep matematika sangat penting bagi sebagai pencapaian pembelajaran lulusan yang meliputi penguasai konsep matematika yang diperlukan untuk melaksanakan pembelajaran di satuan pendidikan dasar, menengah dan menguasai konsep matematika yang diperlukan untuk studi ke jenjang berikutnya. Pemahaman konsep matematis siswa adalah pemikiran siswa dalam memahami konsep matematika sehingga dia dapat menyatakan ulang konsep tersebut, mengklasifikasikan objek menurut sifat tertentu, memberikan contoh dan bukan contoh konsep, menyajikan konsep dalam representasi matematis, menggunakan prosedur tertentu dan mengaplikasikan konsepnya pada pemecahan masalah dalam proses pembelajaran matematika (Mawaddah, 2016). Konsep-konsep yang harus dipahami dalam matakuliah analisis kompleks antara lain : konsep bilangan kompleks, bilangan kompleks dalam bentuk polar, limit dan fungsi kompleks, turunan fungsi kompleks dan integral fungsi kompleks. Dalam memahami konsep-konsep tersebut biasanya mahasiswa kesulitan dalam memahapi konsep turunan fungsi kompleks dan integral fungsi kompleks. Upaya yang dilakukan peneliti untuk meningkatkan kemampuan pemahaman konsep pada mata kuliah analisis kompleks yaitu melalui model pembelajaran mandiri dan menurut peneliti saat ini model pembelajaran mandiri adalah strategi pembelajaran yang tepat dalam mensiasati pembelajaran jarak jauh (PJJ).

Pembelajaran mandiri yaitu salah satu strategi pembelajaran pendidikan yang dilakukan secara individu maupun kelompok di luar pembelajaran tatap muka ataupun tutorial. Pembelajaran mandiri perlu dikelola secara baik oleh tutor maupun pengelola, melalui proses perencanaan secara matang. Pelaksanaannya pembelajaran mandiri mengacu kepada tahap persiapan yang matang, pelaksanaan terkoordinir serta proses penilaian hasil secara akurat, sehingga warga belajar mampu mencapai standar kompetensi yang diharap (Handayani dkk, 2013). Belajar mandiri merupakan kemampuan yang tidak hanya berkaitan dengan pembelajaran apa, tetapi lebih berkaitan dengan bagaimana proses belajar tersebut dilaksanakan. Kegiatan belajar mandiri merupakan salah satu bentuk kegiatan belajar yang menitik beratkan pada kesadaran belajar seseorang dan lebih memberi keleluasaan peserta didik dalam menentukan sendiri cara yang belajarnya dan apa yang ingin di pelajarinya.

Kegiatan pembelajaran dengan model pembelajaran mandiri mampu mengukur beberapa aspek dalam belajar mandiri. Aspek yang diukur dalam kemandirian belajar meliputi pengelolaan diri (selfmanagement), keinginan untuk belajar (desire for learning), dan kontrol diri (selfcontrol). Pembelajaran mandiri juga akan memungkinkan siswa dalam mengatur proses belajar dalam bentuk inisiatif diri, mandiri, pengaturan diri, eksplorasi diri. Pembelajaran mandiri akan memberikan kebebasan kepada siswa dalam kegiatan belajar untuk mengembangkan kemandirian belajar (Putra dkk 2017). Model pembelajaran mandiri dapat memberikan kesempatan mahasiswa untuk lebih mengembangkan potensi yang dimiliki, agar lebih berkembang lagi dalam segala aspek baik kognitif, afektif dan spikomotor. Dimana model Pembelajaran ini lebih mengedepankan managemen diri, keinginan untuk belajar dan mengontrol diri.

Otonomi mahasiswa dalam pembelajaran mandiri (Self-Directed Learning - SDL) secara garis besarnya mencakup 1) planning, 2) monitoring, dan 3) evaluating. Model SDL menyadarkan dan memberdayakan mahasiswa sebagai pembelajar usia dewasa, yaitu belajar adalah tanggung jawab mereka sendiri sehingga proses belajar yang dilakukan juga optimal yang berimbas pada peningkatan hasil belajar (Suardana 2010). Otonomi merupakan kebebasan dalam mengatur segala hal yang berhubungan dengan kegiatan pembelajaran, kewenangan untuk mengatur diri sendiri atau kewenangan 
untuk mengatur diri sendiri supaya tujuan pembelajaran tercapai.

Model pembelajran mandiri memiliki keistimewaan Melalui model pembelajaran mandiri diharapkan kemampuan pemahaman konsep mahasiswa menjadi lebih baik.

Berdasarkan uraian di atas maka peneliti termotivasi untuk melaksanakan penelitian yang berjudul "Analisis Kemampuan pemahanan Konsep Matematis Melalui Model Pembelajaran Mandiri Pada Mata Kuliah Analisis Kompleks". Penelitian ini dilakukan di Universitas Indraprasta PGRI Jakarta kelas 7C semester 7 pada mata kuliah analisa kompleks.

\section{METODE}

Penelitian ini merupakan deskriptif kualitatif yang dilaksanakan di Universitas Indraprasta PGRI dengan subyek penelitian adalah mahasiswa kelas $7 \mathrm{C}$ semester VII dengan jumlah mahasiswa 36 orang dilaksanakan pada semester ganjil tahun ajaran 2020/2021. Pemilihan subjek penelitian dengan mempertimbangkan fokus permasalahan yang dialami pada mahasiswa kelas 7C. Pengumpulan data yang dilakukan dengan cara : 1) memberikan tes, tes diberikan bertujuan untuk mengetahui tingkat kemampuan pemahaman konsep matematika. 2) Observasi, Observasi bertujuan untuk mendeskripsikan model pembelajaran mandiri yang diterapkan pada pembelajaran jarak jauh (PJJ).

Data kemampuan pemahaman konsep matematika mahasiswa diperoleh dengan memeriksa lembar jawaban tes, kemudian data di analisis secara deskriptif kualitatif. Data tersebut digunakan untuk melihat pencapaian kemampuan pemahaman konsep mahasiswa dalam proses perkuliahan.

Tes Kemampuan Pemahaman Konsep Matematis dalam penelitian ini menggunakan instrumen tes berbentuk uraian sebanyak 5 soal dari 5 indikator yang ada untuk mengukur kemampuan pemahaman konsep matematis mahasiswa pada materi pokok bahasan mata kuliah analisa kompleks tersebut. Indikator yang digunakan.

Tabel 1. Indikator Kemampuan Pemahaman Konsep Matematis

\begin{tabular}{|l|l|}
\hline No & Indikator \\
\hline 1. & $\begin{array}{l}\text { Mampu menyajikan situasi matematika ke dalam berbagai cara serta } \\
\text { mengetahui perbedaan }\end{array}$ \\
\hline 2. & $\begin{array}{l}\text { Mampu mengklasifikasikan objek-objek berdasarkan dipenuhi atau } \\
\text { tidaknya persyaratan yang berbentuk konsep tersebut }\end{array}$ \\
\hline 3. & Mampu menerapkan hubungan antara konsep dan prosedur \\
\hline 4. & Mampu memberikan contoh dan kontra dari konsep yang dipelajari \\
\hline 5. & Mampu mengembangkan konsep yang telah dipelajari \\
\hline
\end{tabular}

(Diana, Marethi, dan Pamungkas 2020)

Dilakukan penafsiran untuk menggunakan persentase dari skala likert. menggolongkan tingkat pemahaman konsep

Tabel 2. Kriteria Tingkat Pemahaman Konsep Matematis

\begin{tabular}{|c|c|}
\hline Persentase Skor & Tingkat Pemahaman \\
\hline $0 \%<\mathrm{P} \leq 33,3 \%$ & Rendah \\
\hline $33,3 \%<\mathrm{P} \leq 66,6 \%$ & Sedang \\
\hline $66,6 \%<\mathrm{P} \leq 100 \%$ & Tinggi \\
\hline
\end{tabular}

(Nazir, 2005) 
Tabel 3. Indikator Observasi Model pembelajaran Mandiri

\begin{tabular}{|c|c|c|}
\hline No & Aspek & Indikator \\
\hline \multirow[t]{3}{*}{1.} & \multirow[t]{3}{*}{ Planning (perencanaan) } & $\begin{array}{l}\text { Membuat materi pembelajaran (Power point) } \\
\text { disetiap pertemuan }\end{array}$ \\
\hline & & Membuat video pembelajaran \\
\hline & & Membuat Lembar Kerja Mahasiswa (LKM) \\
\hline \multirow[t]{4}{*}{2.} & \multirow[t]{4}{*}{ Monitoring (pengawasan) } & $\begin{array}{l}\text { Mengecek apakah mahasiswa telah berhasil } \\
\text { melakukan tugas dengan baik, memberi umpan } \\
\text { balik }\end{array}$ \\
\hline & & $\begin{array}{l}\text { Memberikan kesempatan untuk mahasiswa } \\
\text { melakukan tanya jawab ke pada dosen }\end{array}$ \\
\hline & & $\begin{array}{l}\text { Mengecek apakah mahasiswa mengikuti } \\
\text { pembelajaran sesuai jadwal yg ditetapkan }\end{array}$ \\
\hline & & $\begin{array}{l}\text { Mengecek apakah mahasiswa mengumpulkan } \\
\text { tugas tepat waktu }\end{array}$ \\
\hline 3. & Evaluating (evaluasi) & Membuat tugas tersruktur \\
\hline
\end{tabular}

HASIL PENELITIAN DAN $\begin{gathered}\text { Masing-masing aspek yang diamati adalah } \\ \text { sebagai berikut : }\end{gathered}$
PEMBAHASAN

Model pembelajaran mandiri di uji cobakan pada mahasiswa kelas 7C Program studi Pendidikan matematika Universitas Indraprasta PGRI tahun akademik 2020/2021. Pelaksanaan pembelajaran dengan berfokus pada model pembelajaran mandiri menggunakan aplikasi whatsap grup dengan aspek yang diamati berdasarkan beberapa indikator observasi kelas yaitu : 1) planning (perencanaan), 2) monitoring (pengawasan), dan 3) evaluating (evaluasi). Hasil observasi

\section{1) Planning (perencanaan)}

Pada tahapan Planning (perencanaan) ini meliputi media pembelajaran, membuat lembar kerja mahasiswa (LKM) dan alat ukur tes sebagai evalusi pembelajaran. Dosen sudah membuat materi pada setiap pertemuan dalam bentuk power point dan video pembelajaran yang mudah untuk dipelajari oleh mahasiswa. Penampilan pada setiap slide di power point dibuat sedemikian sehingga mahasiswa tidak bosan dengan mengkombinasikan warna, gambar, dan simbol-simbol yang mudah dipahami oleh mahasiswa.

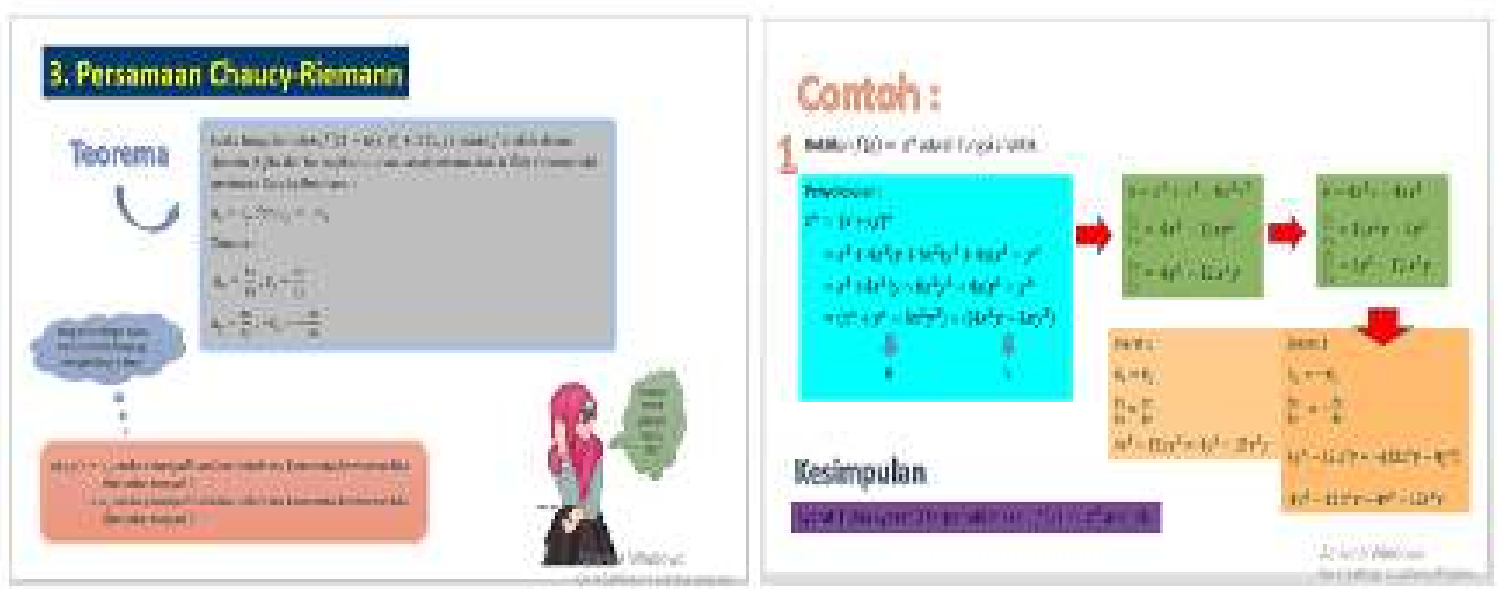

Gambar 1. Contoh power point dalam pembelajaran mandiri 


\section{2) Monitoring (pengawasan)}

Pada tahap Monitoring (pengawasan) mahasiswa diminta untuk mengerjakan soalsoal latihan yang dibuat berdasarkan indikator yang tertulis pada rencana pembelajaran. Soal-soal latihan ini dibuat dalam bentuk Lembar Kerja Mahasiswa (LKM). Pada tahap ini menjadi sangat penting dalam model pembelajaran mandiri karena pada saat mengerjakan soal latihan mahasiswa dilatih untuk inisiatif diri, mandiri, pengaturan diri, eksplorasi diri, berani bertanya, dan berkomunikasi baik dengan teman sejawat ataupun dengan dosen. Antusias mahasiswa dapat dilihat dari seberapa sering mahasiswa bertanya mengenai tugas yang dikerjakan oleh mahasiswa. LKM menjadi menjadi tugas wajib mahasiswa untuk dikumpulkan pada waktu yg sudah ditentukan. contoh tanya jawab mahasiswa dengan dosen.

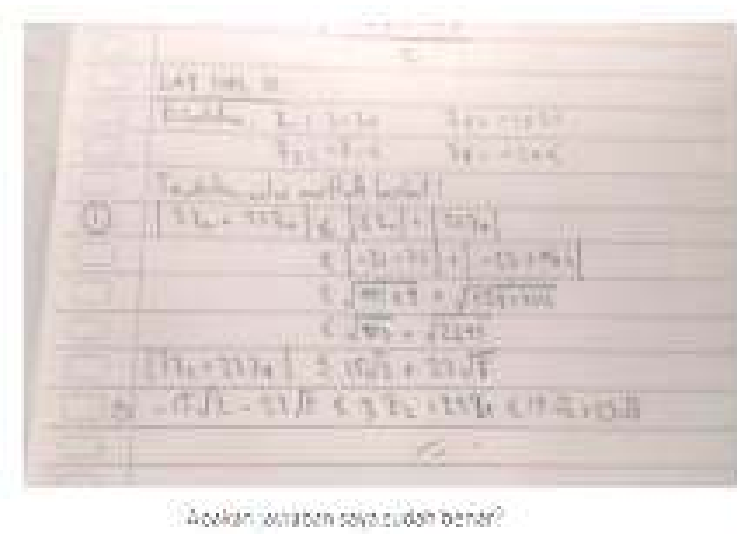

Gambar 2. Contoh tanya jawab mahasiswa dengan dosen sebagai monitoring pembelajaran

\section{3) Evaluating (evaluasi)}

Pada Evaluating (evaluasi) menjadi proses ini sangat penting untuk mengetahui progres dalam pelaksanaan model pembelajaran mandiri. Kegiatan evalusi dilakukan dengan memberikan tugas terstruktur yang berisikan 6 soal yang mencakup seluruh materi pokok bahasan yang telah dipelajari.

Setelah pembelajaran menggunakan model pembelajaran mandiri di seluruh pokok bahasan pada mata kuliah Analisa Kompleks, selanjutnya dilakukan tes kemapuan pemahaman konsep matematis yaitu pada tanggal 14 Januari 2021. Tes dilakukan untuk mengukur tingkat kemapuan pemahaman konsep matematis mahasiswa pada mata kuliah Analisa Kompleks sebagai bahan evaluasi efektif kah? Model pembelajaran mandiri digunakan pada mata kuliah ini. Hasil tes kelas 7C disajikan pada Tabel 3.

Tabel 4. Kemampuan pemahaman Konsep Matematis

\begin{tabular}{|l|l|l|l|}
\hline No & Nilai Akhir Mahasiswa & Frekuensi & Kategori \\
\hline 1 & $0-33$ & 5 & Rendah \\
\hline 2 & $34-66$ & 28 & Sedang \\
\hline 3 & $67-100$ & 3 & Tinggi \\
\hline
\end{tabular}

Dari Tabel 3. di atas diperoleh hasil tes pemahaman konsep matematika mahasiswa menunjukan kategori rendah 13,89\% (5 orang), kategori sedang $77,78 \%$ (28 orang) dan kategori tinggi $8,33 \%$ (3) orang. Sedangkan hasil tes masing-masing indikator kemampuan pemahaman konsep matematis mahasiswa dapat dilihat pada Tabel 5 . 
Tabel 5. Kemampuan Pemahaman Konsep Matematis Mahasiswa Masing-Masing Indikator

\begin{tabular}{|c|l|c|c|}
\hline No. & Indikator kemampuan pemahaman konsep matematis & Prosentase & Kategori \\
\hline 1. & $\begin{array}{l}\text { Mampu menyajikan situasi matematika ke dalam } \\
\text { berbagai cara serta mengetahui perbedaan }\end{array}$ & 40,00 & Sedang \\
\hline 2 & $\begin{array}{l}\text { Mampu mengklasifikasikan objek-objek berdasarkan } \\
\text { dipenuhi atau tidaknya persyaratan yang berbentuk } \\
\text { konsep tersebut }\end{array}$ & 51,67 & Sedang \\
\hline 3 & $\begin{array}{l}\text { Mampu menerapkan hubungan antara konsep dan } \\
\text { prosedur }\end{array}$ & 47,78 & Sedang \\
\hline 4 & $\begin{array}{l}\text { Mampu memberikan contoh dan kontra dari konsep } \\
\text { yang dipelajari }\end{array}$ & 46,11 & Sedang \\
\hline 5 & $\begin{array}{l}\text { Mampu mengembangkan konsep yang telah } \\
\text { dipelajari }\end{array}$ & 28,89 & Rendah \\
\hline
\end{tabular}

Berdasarkan hasil jawaban mahasiswa terhadap tes kemampuan pemahaman konsep matematis mahasiswa, diketahui bahwa mahasiswa masih sangat lemah pada indikator (5) mampu mengembangkan konsep yang telah dipelajari. Prosentase Kemampuan Pemahaman Konsep Matematis sebesar
$28,89 \%$ termasuk dalam kategori rendah. Kesalahan yang dilakukan mahasiswa yaitu mahasiswa tdk mampu menjabarkan turunan fungsi kompleks secara sistematis, dengan menerapkan turunan fungsi kompleks ke dalam konsep fungsi analitik bentuk persamaan Cauchy-Rieamann dengan tepat.

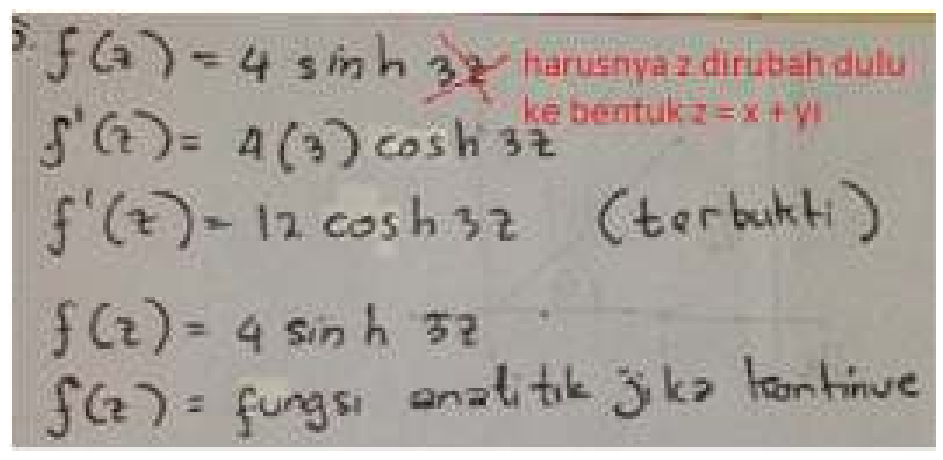

Gambar 3. Jawaban salah pemahaman konsep turunan fungsi kompleks ke dalam konsep fungsi analitik bentuk persamaan Cauchy-Rieamann 


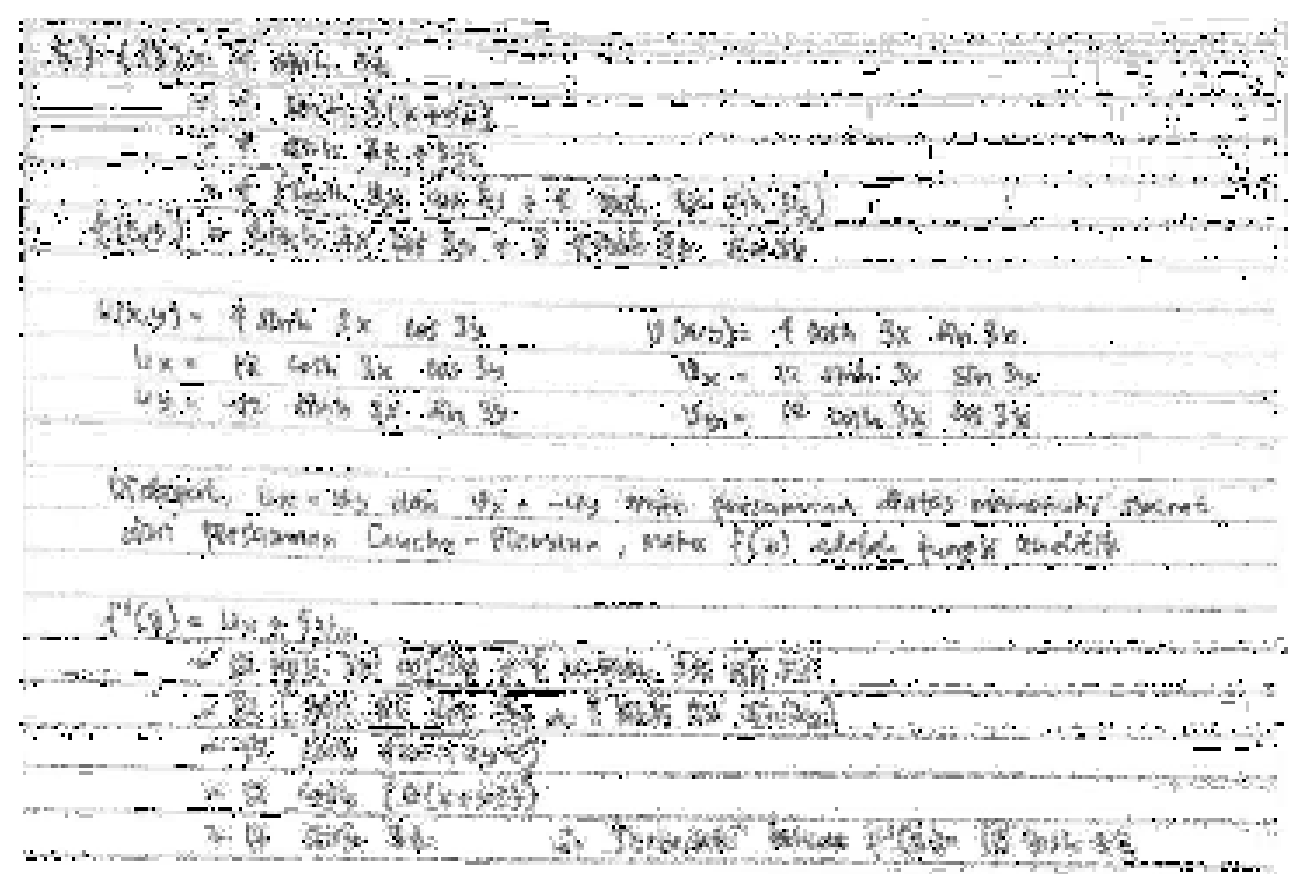

Gambar 4. Jawaban benar pemahaman konsep turunan fungsi kompleks ke dalam konsep fungsi analitik bentuk persamaan Cauchy-Rieamann

\section{SIMPULAN}

Pada bagian ini peneliti akan membahas hasil penelitian yang telah dilakukan oleh peneliti berdasarkan pengumpulan data melalui observasi dan tes kemampuan pemahaman konsep mengenai konsep bilangan kompleks, bilangan kompleks dalam bentuk polar, limit dan fungsi kompleks, turunan fungsi kompleks dan integral fungsi kompleks, maka pembahasan yang akan dijelaskan pada bagian ini yaitu mengenai 1) Langkahlangkah penerapan model pembelajaran mandiri dalam meningkatkan kemampuan pemahan konsep mahasiswa dan 2) Hasil penerapan model pembelajaran mandiri dalam meningkatkan kemampuan pemahaman konsep. Pembahasan dan hasil temuan peneliti akan diuraikan di bawah ini.

Langkah-langkah penerapan model pembelajaran mandiri yaitu berdasarkan proses pembelajaran mandiri meliputi

langkah-langkah seperti 1) planning (perencanaan) pada proses perencanaan yang dilakukan adalah membuat materi/ video pembelajaran dan menyusun lembar kerja mahasiswa (LKM), 2) monitoring (pengawasan) pada proses monitoring dilakukan mahasiswa diminta untuk mengerjakan soal latihan pada LKM, tanya jawab mengenai materi pembelajaran, memastikan mahasiswa aktif mengikuti pembelajaran dan mengkoreksi hasil kerja mahasiswa, dan 3) evaluating (evaluasi) pada proses evalusi dlakukan dengan membuat tugas terstuktur.

Hasil penerapan model pembelajran mandiri pada peningkatan kemampuan pemahaman konsep pada mata kuliah analisis kompleks dapat disimpulkan kemampuan pemahaman konsep matematis mahasiswa termasuk dalam kategori sedang.

Berdasarkan hasil penelitian dan pembahasan mengenai gambaran proses pembelajaran mandiri yaitu langkahlangkah penerapan model pembelajaran mandiri dan hasil penerapan model pembelajaran mandiri. Menunjukan bahwa penerapan model pembelajaran mandiri sudah berjalan dengan baik, akan tetapi masih ada kekurangan dalam beberapa hal, oleh karena itu peneliti menyampaikan beberapa rekomendasi kepada pihak-pihak terkait untuk dijadikan masukan agar mahasiswa lebih giat lagi dalam setiap 
pelaksanaan proses pembelajaran agar tujuan yang ingindicapai dapat tercapai.

\section{REFERENSI}

Diana, P., Marethi, I., Pamungkas, A.S.. (2020). Kemampuan Pemahaman Konsep Matematis Siswa: Ditinjau Dari Kategori Kecemasan Matematik.SJME (Supremum Journal of Mathematics Education) 4(1): 24.

Firman. 2020. Dampak Covid-19 terhadap Pembelajaran diPerguruan Tinggi. Jurnal Bioma, Vol.2, No.1, Juni 2020, Pp. 20https://ojs.unsulbar.ac.id/index.php/bi oma/article/view/743

Handayani, dkk. 2013. Pengaruh Model Pembelajaran Mandiri Terhadap Kemandirian Belajar Dan Prestasi Belajar IPA Siswa Kelas VIII SMP N 3 Singaraja. Jurnal Pendidikan Dasar eJournal Program Pascasarjana Universitas Pendidikan Ganeha 3: 1-10.

Mawaddah, S., dkk. 2016. Kemampuan Pemahaman Konsep Matematis Siswa SMP Dalam Pembelajaran Menggunakan Model Penemuan Terbimbing (Discovery Learning). EDU-MAT: Jurnal Pendidikan Matematika 4(1): 76-85. https://ppjp.ulm.ac.id/journal/index.php/ edumat/article/view/2292/2010.

Nasir, M. 2005. Metode Penelitian. Bogor: Ghalia Indonesia.

Putra dkk. 2017. Penerapan Metode Pembelajaran Mandiri Dalam Meningkatkan Hasil Belajar Peserta Didik (Studi Pada Program Pendidikan Kesetaraan Paket C Di PKBM Bina Mandiri Cipageran)." Jurnal Pendidikan Luar Sekolah 13(1): 23-36.

Suardana, I.K. (2010). Implementasi Model Belajar Mandiri Untuk Meningkatkan Aktivitas, Hasil, Dan Kemandirian Belajar Mahasiswa. Jurnal Pendidikan dan Pengajaran, Jilid 45, Nomor 1, April 2012, hlm.56-65. 